\title{
Percutaneous cecostomy with fully covered self-expandable metal stent for initial management of severe malignant colon obstruction
}

Traditionally, catheter-based percutaneous cecostomy has been utilized in the setting of closed-looped colonic obstruction and in selected patients with fecal incontinence in whom conservative management has failed. Although the procedure is associated with high rates of technical success, complications including catheter migration or dislodgement are common and occur in up to a third of patients. Catheter occlusion and leakage from the catheter site are also common, with leakage often occurring on the skin $(20 \%)$ or within the peritoneum (12\%) [1-5]. Here, we explored the option of using a percutaneous, fully covered, self-expandable, metal stent (FCSEMS) for sequential decompression following malfunction of a percutaneous catheter. In theory, the caliber of the stent would allow improved drainage, while the external flange could be secured with a suture, reducing the risk of migration or dislodgement.

A 44-year-old man with a complex medical history, including heart and kidney transplants and recurrent urothelial cancer, presented with colonic obstruction, secondary to metastasis from the latter, at the level of the ascending colon ( Fig.1a). On computed tomography $(\mathrm{CT})$, the cecum was dilated with solid fecal matter and demonstrated pneumatosis intestinalis of the cecal wall ( $\mathbf{F i g} \mathbf{1} \mathbf{b}, \mathbf{c}$ ). As the patient was a poor surgical candidate, traditional colonic stenting was considered; however, this was deemed unsuitable in view of the high risk of cecal perforation secondary to gas insufflation. Therefore, we opted for placement of a CT-guided percutaneous cecostomy tube as a temporizing measure ( $>$ Fig. 1 d).

While technically successful, the percutaneous cecostomy tube failed to provide significant decompression and the patient experienced both leakage onto the skin and occlusion of the catheter. Thus, we subsequently exchanged the catheter
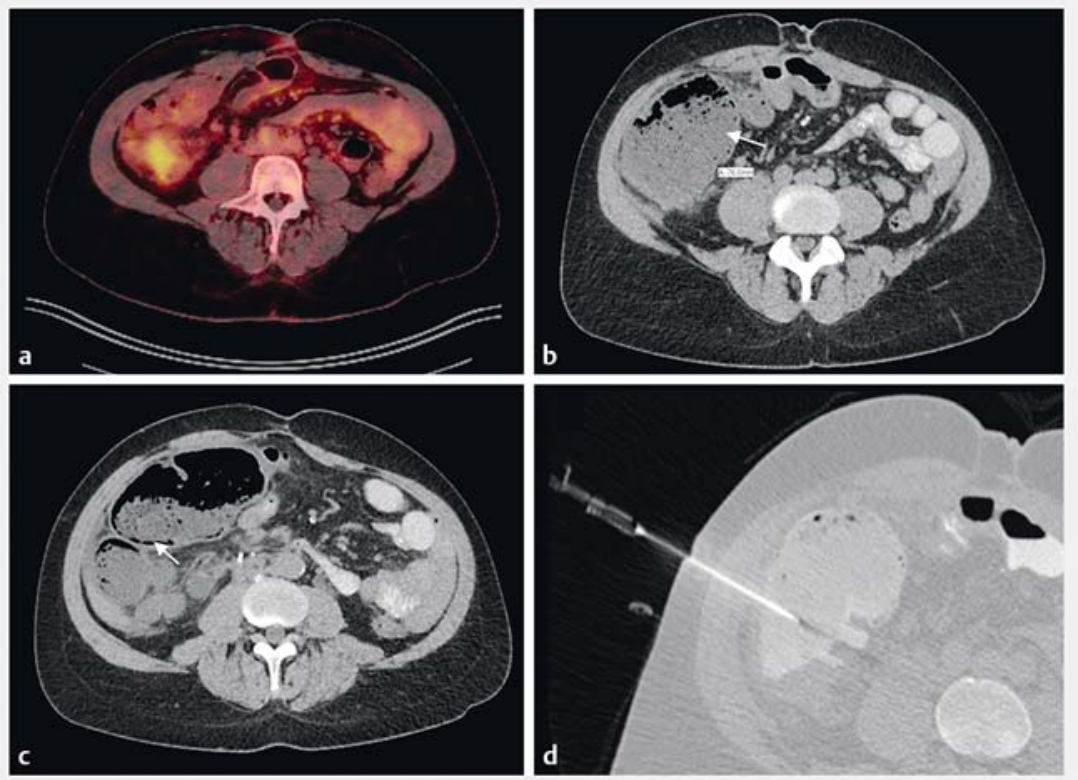

Fig. 1 Positron emission tomography-computed tomography (CT) scan showing: a metastatic lesion at ascending colon; b dilated cecum filled with semi-solid fecal matter (arrow); and $\mathbf{c}$ pneumatosis intestinalis (arrow). d CT-guided percutaneous cecostomy placement.

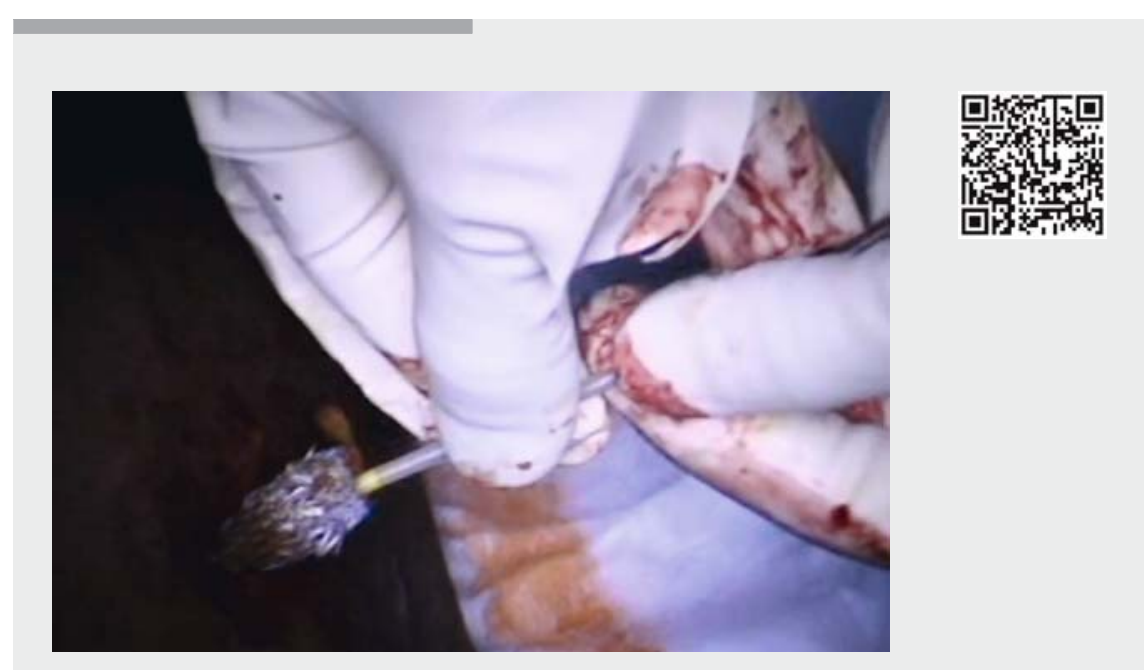

$\checkmark$ Video 1 Percutaneous cecostomy with fully covered self-expandable metal stent for initial management of severe malignant colon obstruction. 

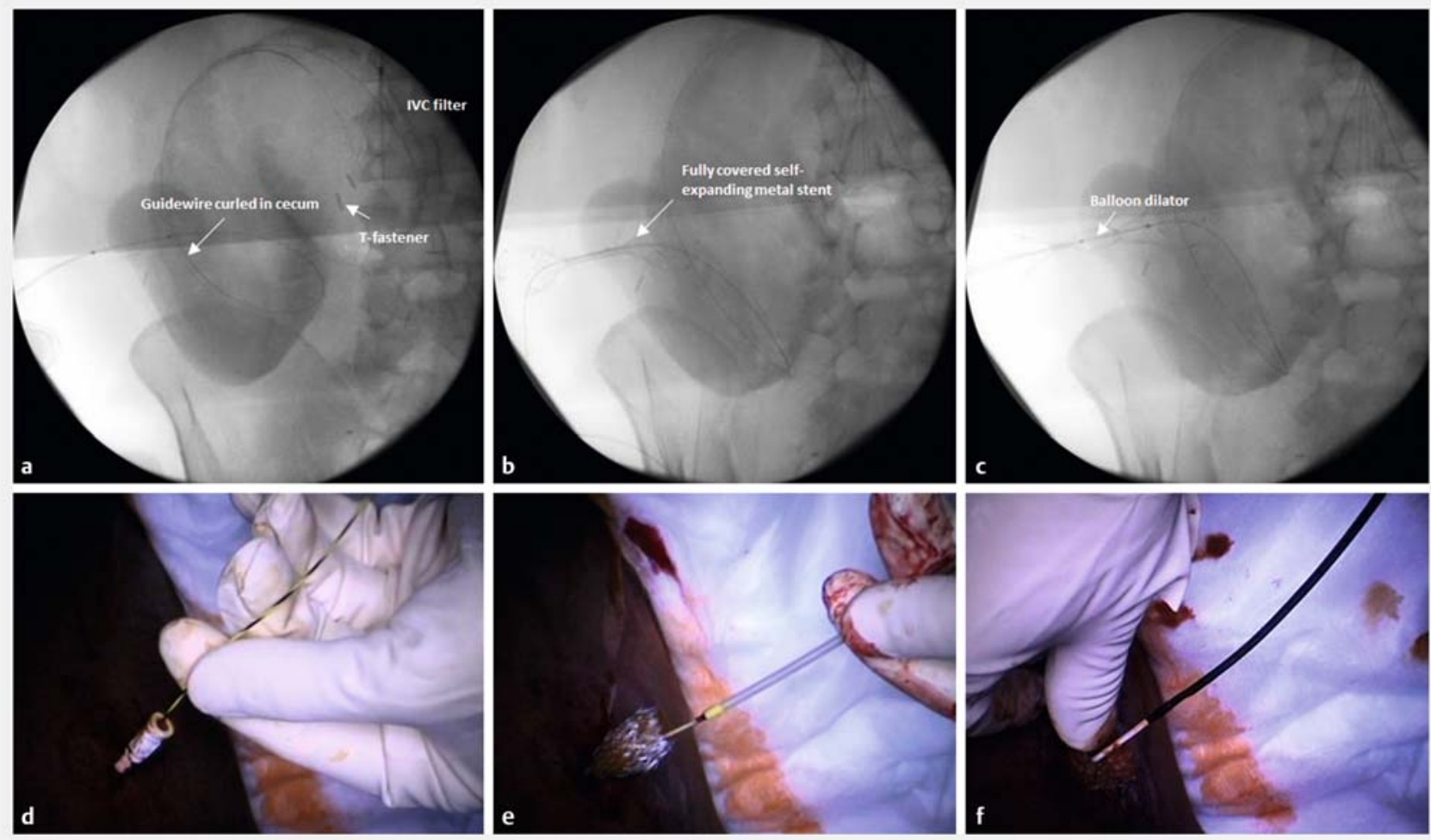

- Fig. 2 Placement of a fully covered, self-expandable, metal stent (FCSEMS). a, d Guidewire inserted through the $5 \mathrm{Fr}$ catheter and curled inside the cecum. b, e FCSEMS deployed under fluoroscopic and direct visualization. c, f Stent dilated with $10 \mathrm{~mm}$ Hurricane balloon.

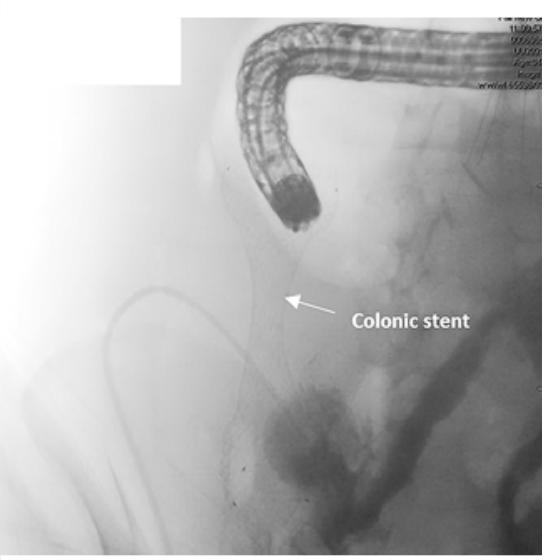

Fig. 3 Colonic stent placed across the obstructing lesion 1 month later.

for an FCSEMS to improve drainage and decompression ( $>$ Video 1 ).

The procedure was performed under general anesthesia, and fluoroscopy was utilized throughout. A long 0.035-inch Jagwire (Boston Scientific, Marlborough, Massachusetts, USA) was placed through the original $5 \mathrm{Fr}$ catheter and curled within the cecum ( $\mathbf{F i g} \cdot \mathbf{2 a}, \mathbf{d}$ ). The catheter was removed over the guidewire, a $1 \mathrm{~cm}$ skin incision was made, and a $4 \mathrm{~mm}$ balloon was used to dilate the tract. Over the wire an $18 \times 60 \mathrm{~mm}$ Niti-S esophageal stent (Taewoong Medical, Gyeonggi-do, South Korea) was deployed, with the distal flange fully expanded inside the cecum and the proximal flange expanded outside of the abdomen ( $\triangleright$ Fig. $\mathbf{2 b}, \mathbf{e}$ ). Stool was seen extruding out of the stent immediately after stent deployment. The stent body was further dilated with a $10 \mathrm{~mm}$ dilator balloon ( $\mathbf{F i g . 2} \mathbf{c}, \mathbf{f}$ ) and the proximal flange was sutured to the skin.

The cecum was successfully decompressed following stent placement. The patient subsequently underwent traditional endoscopic colonic stent placement 1 month later ( $>$ Fig.3). At follow-up, he continued to have relief of his obstructive symptoms. The percutaneous stent was removed and the cecostomy was allowed to close spontaneously without complication.
Percutaneous cecostomy with stent placement presents another minimally invasive option in the management of high risk malignant colonic obstruction. This therapeutic modality should be considered in appropriate high risk cases given the potential decrease in migration, dislodgement, or occlusion when compared with catheter-based approaches.

Endoscopy_UCTN_Code_TTT_1AT_2AZ

Competing interests

None 


\section{Bibliography}

DOI https://doi.org/10.1055/s-0043-119973

Chin Hong Lim ${ }^{1}$, Nicholas M. McDonald², Martin L. Freeman ${ }^{2}$, Stuart K. Amateau ${ }^{2}$

1 Division of Minimally Invasive GI Surgery, University of Minnesota Medical Center, Minnesota, Minneapolis, United States

2 Division of Gastroenterology and Hepatology, University of Minnesota Medical Center, Minnesota, Minneapolis, United States

\section{Corresponding author}

\section{Stuart K. Amateau, MD}

Interventional and Therapeutic Endoscopy, Division of Gastroenterology and Hepatology, University of Minnesota Medical Center, MMC 36-420 Delaware Street SE, Minneapolis, Minnesota 55455, United States

Fax: +1-612-625-5620

amateau@umn.edu

[1] Lynch CR, Jones RG, Hilden K et al. Percutaneous endoscopic cecostomy in adults: a case series. Gastrointest Endosc 2006; 64: 279-282

[2] Marker DR, Perosi N, UI Haq F et al. Percutaneous cecostomy in adult patients: safety and quality-of-life results. J Vasc Radiol 2015; 26: 1526-1532

[3] Chait PG, Shlomovitz E, Connolly BL et al. Percutaneous cecostomy: updates in technique and patient care. Radiology 2003; 227: $246-250$

[4] Donkol RH, Al-Nammi A. Percutaneous cecostomy in the management of organic fecal incontinence in children. World J Radiol 2010; 2: 463-467

[5] Tewari SO, Getrajdman GI, Petre EN et al. Safety and efficacy of percutaneous cecostomy/colostomy for treatment of large bowel obstruction in adults with cancer. J Vasc Interv Radiol 2015; 26: $182-188$
Published online: 9.10.2017

Endoscopy 2017; 49: E313-E315

(c) Georg Thieme Verlag KG

Stuttgart · New York

ISSN 0013-726X

\section{ENDOSCOPY E-VIDEOS}

https://eref.thieme.de/e-videos

口回 Endoscopy E-Videos is a free access online section, reporting 回嗮: on interesting cases and new techniques in gastroenterological endoscopy. All papers include a high quality video and all contributions are freely accessible online.

This section has its own submission website at https://mc.manuscriptcentral.com/e-videos 